more recent investigations. Brief outlines are, however, given of those parts that are not especially treated, in order to maintain continuity and allow of a direct comparison of the properties of the different radiations. Many references are given to original sources, which enable the reader to extend more readily the narrow limits of the book.

The treatise contains an account of a large amount of interesting work, but it can scarcely be expected that one not perfectly familiar with the subject can follow the ideas so briefly expressed in many places.

Throughout the volume we are confronted with a considerable number of misleading and erroneous statements, the nature of which can be seen from a few examples. For instance, on p. 255 it is stated :- "That the rays do not themselves act as conductors seems proved, for they can pass between bodies of very different potentials if these are not already connected by lines of force." Any comment on this is superfluous.

On p. 198 we read :- "The cathode rays possess the same power as the ultra-violet and the X-rays, of causing those gases which they traverse to become conductors of electricity." All careful experiments, however, show that ultra-violet light in traversing a gas does not produce any conductivity.

Again, on p. 259 it is stated that the cha rge carried by the ions in X-ray conduction can be calculated from the values of the saturation current and the time required for the conductivity of the gas to sink to half of its value. Such a calculation is not possible.

On p. 254 , in regard to conduction produced by the passage of X-rays through bodies, we read that "paraffin, wax, sulphur, ebonite, mica, and all gases become conductors." It is now generally believed, however, that solid insulators are not made to conduct by the rays, and the author ignores this side of the question.

Strict accuracy in the facts presented is an essential of every scientific treatise, as the harm produced by the inception of erroneous ideas cannot be over-estimated.

J. Z.

Four-footed Americans and their Kin. By Mabel Osgood Wright. Pp. $\mathrm{xv}+432$; illustrated. (London : Macmillan and Co., Ltd. New York: The Macmillan Company, i 898.)

WHATEVER difference of opinion may obtain as to whether the title of this little volume is the best that could have been found, or whether the "Mr. Barlow" style of "Sanford and Merton" is the most suitable for popular natural history, there can be no hesitation in according the highest praise to the exquisite illustrations which form its most attractive feature. In addition to being in every way artistic productions these, so far as we can judge, are absolutely life-like ; portraying the animals not only among their natural surroundings, but also in characteristic attitudes. Where none are bad, and all attain a high standard of excellence, it is almost invidious to make a selection; but two of the illustrations which especially strike our fancy are the wood-hare on p. I4I, and the little striped skunk on p. 18I. It is rare, indeed, to meet with illustrations of such a high class, and these alone ought to give the book a large sale; while the artist, Mr. E. S. Thompson, ought to obtain a world-wide reputation as a delineator of animal life.

But it is not on the illustrations alone that the book has to depend for popularity ; as, allowing for certain peculiarities in the style, the descriptions of the habits of the various animals mentioned are. for the most part well written and entertaining. A classified synopsis at the end gives a clue to the identification of the species described; and in this connection it is important to notice that in nearly all cases the author is thoroughly up to date as regards nomenclature. As changes in nomen- clature have been necessary, it is most desirable that they should be adopted by popular writers. We must, however, take leave to object to the title of "Beef or Meat Family" for the Bovidae, as also of "Antelope Family" for the Prongbuck, and of "Leapers" for the Leporidae. Since, too, the Viverridae are conspicuous by their absence in America, the misnomer of "Civet-cat" is decidedly objectionable for the Cacomistle (Bassariscus), whose inclusion among the "Cousins of Cats" is scarcely warranted by the facts. As a Christmas present to all young persons interested in animals, the work may be confidently recommended.

R. L.

Electricity made Easy, by Simple Language and Copious Illustration. By Edwin J. Houston, Ph.D., and Arthur E. Kennelly, Sc.D. Pp. 348. (London: Swan Sonnenschein and Co., Ltd., 1898.)

Simple descriptions and explanations of electrical appliances met in every-day life are given in this volume. Facts with regard to the nature and functions of electric mains, the distribution of currents, generating stations, the principles of incandescent and arc lighting, measurement of electric supply, electric bells, telegraphy, telephones, and other things concerned in the production and uses of electricity are stated in the simplest of words. Illustrations are given of the external and internal appear. ance of many of the appliances described. These pictures are, perhaps, a trifle too numerous, for they tend to give the volume the character of a catalogue of electric fittings.

The comparison of the flow of water with the flow of electricity is a useful one; but there is a danger that the reader will carry the analogy too far. On p. 30, for instance, we read that electricity "flows through wires very much like water or gas flows through pipes, but flows through a solid wire as readily as through a tubular wire of the same weight." Brief statements of this kind are frequently the cause of serious misconceptions as to the nature of electricity.

\section{Differential and Integral Calculus for Technical Schools} and Colleges. By P. A. Lambert, M.A., AssistantProfessor of Mathematics, Lehigh University. Pp. $x$ + 245. (New York: The Macmillan Company. London: Macmillan and Co., Ltd., I898.)

THE first hundred pages of this book are occupied with the differentiation and integration of simple algebraic functions, including easy applications to geometry, and here and there a mechanical problem is set amongst the examples.

Then come chapters involving trigonometrical functions, and logarithmic and exponential functions, followed by a chapter containing applications to mass centres and moments of inertia. The next two chapters deal with expansions and applications of Taylor's theorem, and the last forty pages of the work are devoted to an outline discussion of certain simple classes of differential equations.

There are some good features in the book considered as an introductory text-book for ordinary school use where a good deal of supplementary oral teaching would be given. Thus the statement of methods and the proofs, or indications of proof, are clearly worded; the examples are easy and straightforward, and in two or three cases distinctly fresh illustrations appear.

But the general treatment is very superficial ; far too much ground is covered; there is an appearance of easy progress produced by the avoiding of the real difficulties which occur in the practical applications of the calculus. In fact, it is quite misleading to describe the work as specially adapted for technical schools and colleges. No instructor of an English technical class would consider this handbook an adequate introduction to the application of the calculus to physics or engineering. 